\title{
Tıp Fakültesindeki Çoktan Seçmeli Sınav Sorularının Değerlendirilmesi
}

\section{Evaluation of Multiple Choice Questions (MCQ) Exams at Faculty of Medicine}

\author{
Zeliha Cansever ${ }^{1}$, Hamit Acemoğlu², Ümmü Zeynep Avşar ${ }^{2}$, Salih Hoşoğlu $^{3}$ \\ ${ }^{1}$ Mevlana Üniversitesi Tıp fakültesi Tıp Eğitimi ve Bilişimi Anabilim Dalı, Konya \\ ${ }^{2}$ Atatürk Üniversitesi Tıp fakültesi Tıp Eğitimi Anabilim Dalı, Erzurum \\ ${ }^{3}$ Fatih Üniversitesi Mikrobiyoloji Anabilim Dalı
}

\section{ÖZET:}

Amaç: Tıp eğitiminde çoktan seçmeli sorular, yüksek kapsam geçerliliği olması, objektifliği, uygulama ve analizinin kolaylığg nedeniyle sık tercih edilir. Ancak, çoktan seçmeli soru hazırlamak

\begin{abstract}
Anahtar Sözcükler:
Çoktan Seçmeli soru maddeleri, zorluk indeksi, ayırıcılık indeksi
\end{abstract}

Key Words:

Multiple-choice test items, difficulty index, discrimination index ustalık gerektirir. Bu çalışmada Atatürk Üniversitesi Tıp Fakültesi'nde sınavlarda sorulmuş çoktan seçmeli soruların analizinin yapılması (zorluk ve ayırıcılık indeksi) ve Modifiye Bloom Taksonomisi temel alınarak düzeylerinin belirlenmesi amaçlanmıştır. Ayrıca eğitici eğitimi alan ve almayanların soruları, indeks değerlerine göre sınıflandırılmıştır.

Gereç ve Yöntem: Kurul ve final sinavlarından rastgele yöntemle on ayrı sınavdan seçilen 945 soru çalışmaya alındı. Modifiye Bloom Taksonomisine göre düzeyleri belirlendi. Soruların zorluk ve ayırıcılık analizleri yapıldı. Veriler, sayı, yüzde, ortalama ve standart sapma olarak verildi. Sürekli verilerin normallik dağılımı Kolmogorov Smirnov ile test edildi. Verilerin analizinde Ki-kare, bağımsız gruplarda t testi ve tek yönlü ANOVA kullanıldı. Çoklu karşılaştırma Post Hoc LSD testi kullanıld.

Bulgular: İyi ve çok iyi kalitedeki soru oranı toplam \%44,1 $(\mathrm{n}=416)$ idi. Doçentlerin hazırladığ1 sorular yardımcı doçent ve profesörlere göre ayırıcılık indeksi daha yüksek ancak daha kolaydı. Modifiye Bloom Taksonomisine göre soruların büyük bir kısmı hatırlama ve anlama düzeyindeydi. Soruların düzeye göre zorluğunda fark yokken anlama ve değerlendirme düzeylerindeki sorular daha ayırıcı bulundu ( $\mathrm{p}=0,021)$. Öğretim üyelerinin eğitici eğitimi alıp almamaları karşılaştıııldığında eğitim alanların soruları daha kolaydı ve ayrıcılıklarında istatistiksel olarak fark bulunmadı $(\mathrm{p}>0,05)$.

Sonuç: Sınavlardan sonra madde analizlerinin yapılarak öğretim üyelerine bildirilmesi ile soru kalitesinin arttırılması sağlanabilir. Eğiticilerin soru hazırlama için eğitim almaları önemlidir. 


\section{ABSTRACT}

Background: MCQ's are often preferred due to ease of application and analysis, high content validity, and objectivity. But, skill required for preparing of multiple choice questions (MCQ). In this study we determined the difficulty and discrimination indices as well as classify based on Modify Bloom's Taxonomy (BT), by analyzing the multiple choice questions present in the examinations held at Ataturk University Medical Faculty. In addition, we classified the MCQ difficulty and discimination indices between those received training course and not.

Methods: Randomly chosen from ten different committee exams and final exams of 945 questions analyzed. Levels were determined according to the Bloom Taxonomy and were performed difficulty of the questions and discrimination indexes. Data were expressed as the number, percentages, mean and standard deviation (SD). Continuous data normality determined by Kolmogorov-Smirnov test. Data Analyzed using chi-Square and $t$, oneway analysis of variance test. Post Hoc pairwise comparisons were performed using LSD multiple comparisons.

Results: The good quality questions were 44.1\% $(n=416)$. Discrimination index of questions given to Associate professors were higher and easier than compare to Assistant professors and Professors. We assessed difficulty and discrimination index according to the BT level. Greater number of questions were in level of recall and comprehension. Apparently there was no difference in average index of difficulty level in statistically the discrimination index of questions found statistically higher in comprehension and evaluation levels $(p=0,021)$. The difficulty level were found lower in who have received of training course when compared to the group who have not received course. Meanwhile there was no difference questions of discrimination index in these groups.

Conclusions: Quality of questions can be improved by informing faculty members of the post-exam analysis of exam questions. It is therefore imperative that instructors be educated on preparing exam questions.

Sorumlu Yazar: Yrd. Doç. Dr. Zeliha Cansever Mevlana Üniversitesi Tip Fakültesi, Tıp Eğitimi ve Bilişimi Anabilim Dall, Konya

Tel no:4444243(1609)

E-mail: zcansever@mevlana.edu.tr

\section{Giriș:}

Ölçme-değerlendirme eğitimin olmazsa olmaz bir parçası olup öğrenme ve öğretme döngüsünün önemli bir basamağını oluşturmaktadır. Tıp eğitiminde çoktan seçmeli sorular hem mezuniyet öncesi hem de mezuniyet sonrası dönemde yüksek kapsam geçerliliği olması, objektifliği, uygulama ve analizinin kolaylığı nedeniyle sik tercih edilir.

Bloom eğitsel etkinlikleri bilişsel, psikomotor ve duyuşsal olmak üzere üç temel alana ayırmıştır: 2001 yılında revize edilen Bloom taksonomisinde (BT) bilişsel alanda yer alan zihinsel etkinlikler alt basamaktan üst basamağa doğru giderek karmaşıklaşan 6 düzeyde incelenir. $\mathrm{Bu}$ düzeyler sırasıyla; hatırlamak, anlamak, uygulamak, analiz etmek, değerlendirmek ve yaratmak düzeyleridir. Analiz etmek, değerlendirmek ve yaratmak gibi yüksek bilişsel düzeyi test eden soruların hazırlanması için eğitim ve tecrübe gerekir [1]. Öğretme, öğrenme ve ölçme-değerlendirme üzerindeki olumlu etkisi nedeniyle soruların, sınav öncesi gözden geçirilmesi ve sonrasında analiz edilmesi önemlidir.

Genellikle çoktan seçmeli soruların(ÇSS) kavrama ya da uygulamadan daha ziyade bilginin hatırlanmasına yönelik hazırlandığ 
görülmektedir[2]. Miller Piramidinde belirtildiği gibi "bilir" ve "nasılı bilir" basamaklarında kuramsal bilgi temsil edildiğinden ÇSS lar bu basamakların sinanmasinda uygun görünmektedir[3].

Öğrenme eksikliği ve başarısızlığa neden olan faktörlerin belirlenip iyileştirici adımların atılmasını sağlayan çalışmalara 1şık tutması ve mezun olacakların en iyi şekilde değerlendirilmesini sağlamada sınama yöntemleri çok önemlidir [4]. Bu nedenle ölçmedeğerlendirme yöntemlerinin çeşitlendirilmesi gerekir. En sık kullanılan ÇSS sınavlarında da, soruların hatasız hazırlanması ve kaliteli olması beklenir.

Çoktan seçmeli soru hazırlanmasında üç önemli nokta üzerinde durulmaktadır: a) öğrenim hedeflerinin yazılması, (b) her hedef için öğrenme düzeylerinin belirlenmesi ve (c) öğrenmeyi test etmede etkili çoktan seçmeli sorular hazırlanması. İdeal çoktan seçmeli sorular hazırlamak ustalık gerektirir [5]. T1p fakültelerinde eğiticilerin eğitim becerilerini geliştirmeye yönelik programlar uygulanmakta [6], bu programlar içerisinde ÇSS hazırlama teknikleri ile ilgili eğitimler de verilmektedir [7].

$\mathrm{Bu}$ çalı̧̧̧mada Atatürk Üniversitesi Tip Fakültesi'nde sınavlarda sorulmuş çoktan seçmeli soruların analizi yapıldı (zorluk ve ayırıcılık indeksi) ve Bloom taksonomisine göre sınıflandırılması amaçlandı.

\section{Gereç-Yöntem}

Fakültemizde test otomasyonu sistemi olan Sinavmatik® 2010 yilından beri (http:// www.pilotltd.com/) kullanılmakta olup soru bankasında yaklaşık 35.000 adet soru bulunmaktadır. Üniversitemizde eğitim dili Türkçe ve İngilizce olan 2 ayrı tıp fakültesi bulunmaktadır. 2012-2013 yılı içinde fakültemizin ilk 3 sınıfinda uygulanan kurul ve final sınavlarından rastgele yöntemle on ayrı sınavdan seçilen soruların analizi yapıldı. Tıp eğitimi anabilim dalı öğretim üyelerince eğitici eğitimi alanlar ve almayanların listesi çıkarıldı. BT'ye göre soruların düzeyleri belirlendi ve madde analizi yapıldı. Bağımlı değişken olarak soru kalitesinde "çıkarılmalı", "geliştirilmeli", "iyi" ve "çok iyi" kategorileri ile soruların zorluk ve ayırıcılık indeksleri yanında Modifiye BT düzeyleri ( hatıllamak, anlamak, uygulamak, analiz etmek, değerlendirmek ve yaratmak yer almaktaydı. Bağımsız değişken olarak ise cinsiyet (K,E), sinfflar (1.,2.ve 3.), eğitim programının dili ( Türkçe ve İngilizce), ünvanlar (Yrd. Doç., Doç.,Prof.), eğitici eğitimi alma ve almama durumu yer almaktaydı.

Soru bankası yazılımı ayırıcılık, güçlük ve kalite analizlerini aşağıda tanımlanan kriterleri göre yapmaktadır.

Ayırıcılı: Maddenin ayırıc1lı indeksi, -1 ile +1 arasındaki bu sayı, maddenin yüksek puanlı ve düşük puanlı öğrencileri ayırmada ne derece etkili olduğunu ortaya çıkarır. İyi ayırabilen bir madde için bu değerin $+0,4$ 'ten büyük olmas1 gerektiği kabul edilir. Negatif ayırıcılıklı sorular ise görevini yapamamış kabul edilir ve testlerde kullanılmamalıdır.

Zorluk: Maddenin güçlük düzeyi, 0 ile +1 arasındaki bu sayı, maddeye doğru yanıt verenlerin oranını verir. $\mathrm{Bu}$ oran zor sorularda 0 'a, kolay sorularda ise +1 'e yakın çıkar. Maddenin testte kullanım amacına göre değişmekle birlikte, güçlük düzeyi $0,2^{\prime}$ den küçük ve $0,8^{\prime}$ 'den büyük maddelerin testlerde kullanılmaması gerektiği kabul edilir.

Kalite: Maddenin kalite yorumu, sistem, maddenin ayırıcılık indeksi ve güçlük düzeyine bakarak kullanılabilirliğine ilişkin bir kalite yorumu yapar. Bu yorum aşağıdaki dört seviyeden birini alır: 3 - Çok iyi madde: Ayırıc1lı indeksi $+0,4$ 'ten büyük, güçlük düzeyi de 0,15 ile 0,85 arasında. 2 - İyi madde: Ayırıc1lık indeksi $+0,3$ ile $+0,4$ arasında, güçlük düzeyi de 0,15 ile 0,85 arasında. 1 - Düzeltilerek kullanılabilir: Ayırıcılık indeksi 0,2 'den büyük ancak güçlük düzeyi $0,15-0,85$ aralı̆̆ının 
dışında kalanlar. 0 - Kötü madde: Testlerde kullanılmamalı. Ayırıcılık indeksi +0,2'den küçük. Veriler, say1, yüzde, ortalama ve standart sapma olarak verildi. Veriler IBM SPSS 20.0 bilgisayar istatistik programına girilerek analiz edildi. Sürekli verilerin normallik dağılımı Kolmogorov Smirnov ile test edildi. Verilerin analizinde Ki-kare, bağımsız gruplarda $t$ testi ve tek yönlü ANOVA kullanıldı. Çoklu karşılaştırma Post Hoc LSD testi kullanıldı. İstatistik önemlilik düzeyi $\mathrm{p}<0,05$ alınd.

\section{Bulgular}

Araştırmada toplam 945 soru incelenmiş olup, bunların 779 tanesi $(\%$ 82,4) erkek öğretim üyeleri tarafından hazırlanmıştı. Soruların 640 tanesi $(\% 67,7)$ Türkçe eğitim programından olup bunların 399'u $(\% 42,2)$ birinci sinif sınavlarına aitti. İncelenen 26 farklı anabilim dalından 135 öğretim üyesinin hazırladığ soruların $458(\% 48,5)$ tanesi profesör unvanına sahip öğretim üyelerine aitti. Eğitici eğitimi alan öğretim üyeleri tarafindan hazırlanan soru sayısı $783(\% 82,9)$ idi (Tablo 1).

\begin{tabular}{|c|c|c|c|}
\hline \multicolumn{2}{|l|}{ Özellik } & \multirow{2}{*}{$\begin{array}{l}\mathbf{n} \\
779\end{array}$} & \multirow{2}{*}{$\begin{array}{c}\% \\
82,4\end{array}$} \\
\hline Öğretim üyesi cinsiyet & Erkek & & \\
\hline & Kadın & 166 & 17,6 \\
\hline Programinin & Türkçe & 640 & 67,7 \\
\hline dili & Îngilizce & 305 & 32,3 \\
\hline \multirow[t]{3}{*}{ Sinif } & $1 . \sin u f$ & 399 & 42,2 \\
\hline & 2.sinif & 193 & 20,4 \\
\hline & 3.sinif & 353 & 37,4 \\
\hline \multirow[t]{3}{*}{ Unvan } & Brof.Dr. & 458 & 48,5 \\
\hline & Doç. Dr. & 263 & 27,8 \\
\hline & Yrd. Doç. Dr. & 224 & 23,7 \\
\hline \multirow[t]{2}{*}{ Eğitici eğitimi } & Almış & 783 & 82,9 \\
\hline & Almamıș & 162 & 17,1 \\
\hline \multirow[t]{11}{*}{ Sinavlar } & 1 & 34 & 3,6 \\
\hline & 2 & 231 & 24,4 \\
\hline & 3 & 116 & 12,3 \\
\hline & 4 & 59 & 6,2 \\
\hline & 5 & 56 & 5,9 \\
\hline & 6 & 66 & 7,0 \\
\hline & 7 & 44 & 4,7 \\
\hline & 8 & 171 & 18,1 \\
\hline & 9 & 82 & 8,7 \\
\hline & 10 & 86 & 9,1 \\
\hline & Total & 945 & 100,0 \\
\hline
\end{tabular}


Soruların zorluk ve ayırıcılık indeksleri incelendiğinde $274 \quad(\% 29)$ sorunun testten çıkarılması, $255(\% 27,0)$ sorunun geliştirilmesi gerektiği bulundu (Tablo 2). Soruların ortalama zorluk ve ayırıcilık indeksleri sirasıly $0,64 \pm 0,25$ ve $0,29 \pm 0,18$ bulundu.

Tablo 2. Soruların zorluk ve ayuacılık indekslerine göre sinıflandırılması

\begin{tabular}{|c|c|c|}
\hline & $\mathbf{n}$ & $\%$ \\
\hline Çıkarılmalı & 274 & 29,0 \\
\hline Geliştirilmeli & 255 & 27,0 \\
\hline İyi & 164 & 17,4 \\
\hline Çok İyi & 252 & 26,7 \\
\hline Total & 945 & 100,0 \\
\hline
\end{tabular}

Soruların Modifiye Bloom taksonomisine göre düzeylerinin dağılımı incelendiğinde 502 $(\% 53,1)$ soru hatırlamak, $273(\% 28,9)$ soru anlamak, $107(\% 11,3)$ soru uygulamak,33(\%3,5) soru analiz etmek ve $30(\% 3,2)$ sorunun ise değerlendirme düzeyinde olduğu bulundu (Şekil $1)$.

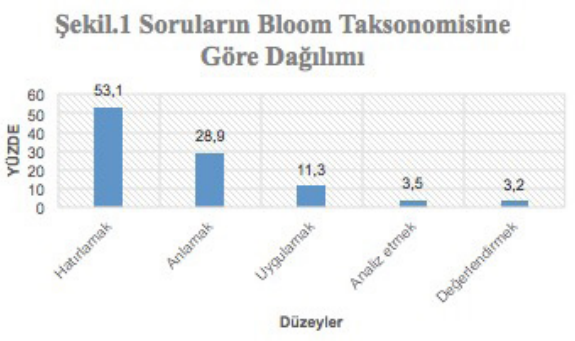

Soruları hazırlayan öğretim üyelerinin cinsiyeti, unvanı ve eğitici eğitimi alma durumu, eğitim programının dili ve sınıflara göre soru kalitesinin dağılımı incelendiğinde erkek ve kadın öğretim üyelerinin hazırladıkları soruların "çok iyi" dağılımı sırasıyla \%28,8 ve $\% 16,9$ bulundu $(\mathrm{p}=0,001)$. Öğretim üyelerinin unvanları ve eğitici eğitimi alıp almamaları karşılaştırıldığında istatistiksel olarak fark bulunmad1 $(p>0,05)$. Eğitim program dili İngilizce ve Türkçede "çok iyi” madde dağılımı sirasiyla \%37,7 ve \%21,4 bulundu $(p<0,001)$. 1 , 2., ve 3. sınıflara göre "çok iyi" madde dağılımı sirasiyla $\% 29,1$ ve $\% 36,8$ ve $\% 18,4$ bulundu $(\mathrm{p}<0,001)$ (Tablo 3).

Soruları hazırlayan öğretim üyelerinin cinsiyeti, unvanı ve eğitici eğitimi alma durumu, eğitim programının dili ve sinıflara göre zorluk ve ayırıcılık indeksleri incelendi. Erkek ve kadın öğretim üyelerinin hazırladıkları soruların ayırıcılık indeks ortalamaları sirasıyla $0,30 \pm 0,18$ ve $0,25 \pm 0,16$ olup fark istatistiksel olarak anlamlı bulundu $(\mathrm{t}=3,13 ; \mathrm{p}=0,002)$.

Doçent unvanına sahip öğretim üyelerinin hazırladıkları soruların zorluk ve ayırıcılık indeksleri profesör ve yardımcı doçent unvanına sahip öğretim üyelerinden daha ayırıcı ve kolay bulundu $(\mathrm{p}<0,05)$.

Eğitim program dili Türkçe ve İngilizcede hazırladıkları soruların ayırıcılı indeks ortalamaları sirasiyla $0,27 \pm 0,16$ ve $0,33 \pm 0,19$ olup fark istatistiksel olarak anlamlı bulundu $(\mathrm{t}=4,87 ; \mathrm{p}<0,001)$.

Birinci sınıf sınavlarının zorluk indeksi diğer sınıflardan istatistiksel olarak daha düşük bulundu $(\mathrm{p}<0,05)$, ikinci sınıfın ayırıcilık indeksi ise diğer sınıflardan daha yüksek bulundu $(\mathrm{p}<0,05)$ (Tablo 4$)$. 
Tablo 3. Soruları hazırlayan öğretim üyelerinin bazı değișkenlere göre soru kalitesinin dağı̆lımı

\begin{tabular}{|c|c|c|c|c|c|c|c|c|c|c|c|}
\hline & & \multicolumn{8}{|c|}{ Zorluk ve ayracılık indekslerine göre sınıflandırılması } & \multirow[b]{3}{*}{$x^{2}$} & \multirow[b]{3}{*}{$p$} \\
\hline & & \multicolumn{2}{|c|}{ Çıkarılmalı } & \multicolumn{2}{|c|}{ Geliştirilmeli } & \multicolumn{2}{|l|}{ İyi } & \multicolumn{2}{|c|}{ Çok İyi } & & \\
\hline & & $\bar{n}$ & $\%$ & $\mathrm{n}$ & $\%$ & $\mathrm{n}$ & $\%$ & $\mathrm{n}$ & $\%$ & & \\
\hline \multirow{2}{*}{ Cinsiyet } & Erkek & 211 & 27,1 & 217 & 27,9 & 127 & 16,3 & 224 & 28,8 & \multirow{2}{*}{16,9} & \multirow{2}{*}{0,001} \\
\hline & Kadın & 63 & 38,0 & 38 & 22,9 & 37 & 22,3 & 28 & 16,9 & & \\
\hline
\end{tabular}

\begin{tabular}{|c|c|c|c|c|c|c|c|c|c|c|c|}
\hline Eğitim & Türkçe & 198 & 30,9 & 188 & 29,4 & 117 & 18,3 & 137 & 21,4 & \multirow[b]{2}{*}{28,3} & \multirow[b]{2}{*}{0,000} \\
\hline $\begin{array}{l}\text { Programının } \\
\text { dili }\end{array}$ & Îngilizce & 76 & 24,9 & 67 & 22,0 & 47 & 15,4 & 115 & 37,7 & & \\
\hline \multirow[t]{3}{*}{ Sinif } & $1 . \sin i f$ & 121 & 30,3 & 86 & 21,6 & 76 & 19,0 & 116 & 29,1 & & \\
\hline & 2.sinif & 33 & 17,1 & 53 & 27,5 & 36 & 18,7 & 71 & 36,8 & \multirow[t]{2}{*}{41,1} & 0,000 \\
\hline & 3. sinif & 120 & 34,0 & 116 & 32,9 & 52 & 14,7 & 65 & 18,4 & & \\
\hline \multirow{4}{*}{ Unvan } & Prof.Dr. & 142 & 31,0 & 124 & 27,1 & 78 & 17,0 & 114 & 24,9 & \multirow{4}{*}{8,7} & \multirow{4}{*}{0,194} \\
\hline & Doç. Dr. & 66 & 25,1 & 70 & 26,6 & 41 & 15,6 & 86 & 32,7 & & \\
\hline & Yrd. & 66 & 29,5 & 61 & 27,2 & 45 & 20,1 & 52 & 23,2 & & \\
\hline & Doc:Dr. & & & & & & & & & & \\
\hline Eğitici & Aldı & 226 & 28,9 & 222 & 28,4 & 129 & 16,5 & 206 & 26,3 & \multirow{2}{*}{5,5} & \multirow{2}{*}{0,142} \\
\hline eğitimi & Almadı & 48 & 29,6 & 33 & 20,4 & 35 & 21,6 & 46 & 28,4 & & \\
\hline
\end{tabular}


Tablo 4. Soruları hazırlayan öğretim üyelerinin bazı değișkenlere göre soruların zorluk ve ayırt edicilik indeksleri.

\begin{tabular}{|c|c|c|c|c|c|c|c|c|}
\hline & & & \multicolumn{3}{|l|}{ Zorluk } & \multicolumn{3}{|c|}{ Axuraceluk } \\
\hline & & & Mean & SD & $\mathrm{P}$ & Mean & SD & $\mathrm{P}$ \\
\hline \multirow{2}{*}{\multicolumn{2}{|c|}{ Cinsiyet }} & Erkek & 0,64 & 0,25 & \multirow[b]{2}{*}{0,76} & 0,30 & 0,18 & \multirow[b]{2}{*}{0,002} \\
\hline & & Kadın & 0,63 & 0.23 & & 0,25 & 0,16 & \\
\hline Eğitim & \multirow[t]{2}{*}{ Programinın } & Türkçe & 0,63 & 0,25 & \multirow[b]{2}{*}{0,5} & 0,27 & 0,16 & \multirow[b]{2}{*}{0,000} \\
\hline dili & & Îngilizce & 0,65 & 0,25 & & 0,33 & 0,19 & \\
\hline \multirow[t]{3}{*}{ Sinif* } & & 1.sinif & $0,59^{\text {ab }}$ & 0,25 & & $0,29^{a}$ & 0,20 & \\
\hline & & 2.sinif & $0,69^{2}$ & 0,23 & 0,000 & $0,34^{\text {ab }}$ & 0,15 & \multirow[t]{2}{*}{0,000} \\
\hline & & 3. sinif & $0,66^{\circ}$ & 0,24 & & $0,26^{b}$ & 0,14 & \\
\hline \multirow{3}{*}{\multicolumn{2}{|c|}{ Unvan* }} & Prof. & 0,62 & 0,25 & & 0,28 & 0,17 & \multirow{3}{*}{0,001} \\
\hline & & Doç. & $0,69^{a}$ & 0,23 & 0,000 & $0,32^{a}$ & 0,19 & \\
\hline & & Yrd. Doc & 0,61 & 0,26 & & 0,28 & 0,16 & \\
\hline
\end{tabular}

$\begin{array}{llllllll}\text { Eğitici eğitimi } & \text { Aldı } & 0,64 & 0,25 & & 0,29 & 0,18 & \\ & & & & 0,039 & & & 0,569 \\ & \text { Almadı } & 0,60 & 0,25 & & 0,30 & 0,16 & \end{array}$

SD=Standard Deviation

Karsulasturma ANOVA ile yapuldu ve coklu karslasturmalar icin post hoc LSD kullanuld.

a ve b icin $p<0,05$ 
Soruların Modifiye Bloom Taksonomisi karşılaştırma analizinde hatırlamak ve anlamak düzeyine göre zorluk ve ayırıcılık indeksleri ile anlamak ve değerlendirmek grupları arasında incelendi. Düzeylerin ortalama zorluk indeksleri arasinda istatistiksel olarak fark bulunmazken ( $p>0,05)$ ayırıcılık indeks ortalamaları arasında istatistiksel olarak önemli fark olduğu bulundu $(\mathrm{p}=0,021)$. Yapılan post hoc LSD çoklu istatistiksel olarak önemli derecede fark bulundu $(\mathrm{p}<0,05)$ (Tablo 5).

Sinavlarda sorulan bazı örnek soruların Mofifiye BT'ye göre düzeyleri tablo 6' da verilmiştir.

Tablo 5. Soruların Mofifive Bløem Taksonomisi düzeyine göre zorluk ve ayuruculık indeksleri.

Zorluk

Düzey

Hatırlamak $(\mathrm{n}=502)$

Anlamak $(\mathrm{n}=273)$

Uygulamak $(\mathrm{n}=107)$

Analiz etmek $(n=33)$

Değerlendirmek $(\mathrm{n}=30)$

\begin{tabular}{ccc}
\hline Ortalama & SS & p \\
\hline 0,65 & 0,25 &
\end{tabular}

0,63

0,24

$0,62 \quad 0,25$

0,095

$0,55 \quad 0,25$

$0,67 \quad 0,25$
Avaruculık.

\begin{tabular}{ccc}
\hline Ortalama & SS & p \\
\hline $0,28^{\mathrm{a}}$ & 0,18 &
\end{tabular}

$0,32^{\text {ab }} \quad 0,17$

$0,29 \quad 0,16$

0,021

$0,26 \quad 0,15$

$0,25^{\mathrm{b}} \quad 0,15$

SS: Standart Sanma, a icin $\mathrm{p}=0.004$ b icin $\mathrm{p}=0,04$

*Karsulasturma ANOVA ile yapuldı ve soklu karsulasturmalar icin LSD kullanuld. 
Sınavlarda sorulan bazı örnek soruların Mofifiye BT've göre düzeyleri tablo 6'da verilmistir.

\begin{tabular}{|c|c|}
\hline Bloom Düzeyi & Ömek \\
\hline Hatırlamak & $\begin{array}{l}\text { Aşağıdaki oluşumlardan hangisi ön kolun medialindeki kemik olan } \\
\text { Ulna'da bulunur? } \\
\text { A) Olecranon } \\
\text { B) Fossa olecrani } \\
\text { C) Incisura ulnaris } \\
\text { D) Epicondulus medialis } \\
\text { E) Capitulum }\end{array}$ \\
\hline Anlamak & $\begin{array}{l}\text { Düz kaslarda kalsiyum, kontraksixonu başlatıcı etkinliğini } \\
\text { aşağıdakilerden hangisine bağlanarak yapar? } \\
\text { A) Troponin C } \\
\text { B) Aktin } \\
\text { C) Mivozin } \\
\text { D) Kalmodulin } \\
\text { E) Tropomiyozin }\end{array}$ \\
\hline Uygulamak & $\begin{array}{l}25 \mathrm{~mm} / \mathrm{s} \text { hızla çekilen bir elektrokardiyografide eşit aralıklarla gelen iki } \\
\text { QRS kompleksi arasında } 25 \text { küçük kare bulunmaktadır. Bu kişinin }\end{array}$ \\
\hline
\end{tabular}




\begin{tabular}{|c|c|}
\hline & $\begin{array}{l}\text { dakikada nabız sayısı kaçtır? } \\
\text { A) } 25 \\
\text { B) } 40 \\
\text { C) } 60 \\
\text { D) } 80 \\
\text { E) } 100\end{array}$ \\
\hline Analiz Etmek & $\begin{array}{l}\text { Belirgin skuam, papillomatöz ve akantozun görüldüg̈ü hastalıktır? } \\
\text { A) Liken Planus } \\
\text { B) Eritema Multiforme } \\
\text { C) Psöriazis } \\
\text { D) Liken Simpleks Kronikus } \\
\text { E) Hiçbiri }\end{array}$ \\
\hline Değerlendirmek & $\begin{array}{l}45 \text { yaşında erkek hasta, } 3 \text { gün boyunca ateş, nefes almada zorluk ve } \\
\text { balgamlı öksürük şikayeti var. Fizik muayenede ates } 38.5^{\circ} \text { C'dir. } \\
\text { Akciğer grafisinde sağ pleyral effüzxon tespit ediliyor ve sağ torasentez. } \\
\text { yapılıyor. Elde edilen sıvının incelenmesinde bulanık bir görūnüme } \\
\text { sahip nōtrofiller \% } 98 \text { oranında ve mikrolitre başına } 17.000 \text { olarak } \\
\text { belirleniyor. Mevcut pleyral inflamasyonu aşağıdaki terimlerin hangisi } \\
\text { en iyi açıklar? } \\
\text { A) Seröz inflamasyon } \\
\text { B) Rürülan inflamasyøn } \\
\text { C) Eibrinöz inflamasyon }\end{array}$ \\
\hline & $\begin{array}{l}\text { D) Kronik inflamasyon } \\
\text { E) Granülomatōz inflamasyon }\end{array}$ \\
\hline
\end{tabular}




\section{Tartışma}

Madde analizi sinavlardan sonra yapilan ve sınavların sorularının kalitesini belirleyen basit fakat etkili bir yöntemdir. İdeal bir sınavda zorluk indeksi \%31-60 arasında, ayırıcılık indeksi de \%25ten fazla olmalıdır[8]. Bizim sınavlarımızda da ayırıcılık indeksi ortalaması 0.25 'in üzerinde bulundu.

Sınavlarımızda erkeklerle bayan öğretim üyelerinin sorularında zorluk yönünden fark yokken erkek öğretim üyelerinin sorularının ayırıcılık indeks değerleri daha yüksek bulundu. Fakültemizde İngilizce ve Türkçe tıp soruları bakımından İngilizce tıp sorularının ayırıcılık indeks değerleri daha yüksek bulundu.

Ayrıca doçent düzeyindeki öğretim üyelerinin soruları daha ayırıcı ve zorluk indeks değerleri daha yüksekti. Soru sorma bir sanattır. Aceleyle hazırlanan sorular soru kalitesini etkilemekte ve belirsizliklere, yanlış anlaşılmalara neden olabilmektedir. Hatta bazı kurumlarda soruların gözden geçirilmesi ile ilgili bölümler oluşturulduğundan ve soruların içeriği, teknik özelliği, gramer yapısı, şıkların içeriği editöryel değerlendirilmesinin yapıldığından bahsedilmektedir[9]. Bu süreç tıpkı atın koşu öncesi bakımının yapılmasına benzetilmiş ve "Vetting" kelimesi ile ifade edilmiştir. Bizim sınavlarımızda da soruların gözden geçirilmesi tıp eğitimi anabilim dalı, dekanlık ve eğitim koordinatörünün işbirliği ile yapılmaktadır. Ayrıca İngilizce yönünden de sorular tek tek gözden geçirilmektedir.

Bir çalışmada Mini essay sorulara göre ÇSS ların daha üstün olduğu belirtilmekte ve öğretim üyelerinin soru hazırlamada hatalarının olmaması için eğitim almaları gerektiğinden bahsedilmektedir[10]. Bizim çalışmamızda ise eğitici eğitimi alanların soruları daha zor idi ve ayırıcılık indeksleri arasında ise fark bulunmamaktaydı. Eğitici eğitimi almış olmak soru kalitesini etkilemiyordu. Bulgularımız eğitici eğitiminin bir kez alınmasının yeterli olmadığını ve soru kalitesi ile ilgili eğitimlere ağırlık verilmesi gerektiğini düşündürmektedir.
Test maddelerinin bilişsel öğrenme düzeylerinin belirlenmesi gerektiğinden bahsedilmektedir[11].

Sinavlarımızın değerlendirme sonrası madde analizleri yapılmış ve öğrenme düzeyleri de incelenmişti. Soruların büyük kısmı sırasıyla hatırlamak, anlamak ve uygulamak düzeylerinden oluşmuştu. En az kısmı ise analiz etmek düzeyindeki sorulardan oluşmaktaydı. Öğrencilerimizin farklı farklı öğrenme stilleri mevcuttur. Bilişsel alandaki hatırlamak (bilgi) düzeyini sınamaya yönelik sorular genellikle ezbere ve hatırlamaya dayalı sorulardır. Anlamak (kavrama) düzeyindeki sorular; hesaplama, gruplama ve seçme gibi alanları, uygulamak; yorumlama, kullanma ve çözme, analiz etmek; ayırt etme, ölçme, sınıflandırma, değerlendirme düzeyi karar verme, tayin etme, tahmin etme, eleştirme yaratmak (sentez) ise; tasarlama, geliştirme ve açıklama gibi konuları içermektedir[12]. İlk üç sınıfta çoğunlukla temel bilim dersleri verildiğinden dolayı daha çok hatırlama ve anlamaya yönelik soru sorulmuş olabilir. Fakat yine de üst bilişsel düzey sorularına da yer verilmesi gerektiği görülmektedir.

\section{Sonuç}

Çoktan seçmeli sorular hangi BT düzeyinde olursa olsun hala ölçme -değerlendirmede s1k tercih edilen bir yöntemdir. Ölçme ve değerlendirme eğitimin önemli bir parçasıdır. Sinavlardan sonra madde analizlerinin yapılarak öğretim üyelerine bildirilmesi ile soru kalitesinin arttırılması sağlanabilir. Eğiticilerin soru hazırlama için eğitim almaları önemlidir.

\section{Çalışmanın Kısıtlılığı}

Soruların düzeyleri konusunda görüş ayrılığı olması çalışmanın kısıtlılığını oluşturmaktadır. Ayrica düzeyler bilgi boyutunda olgusal, kavramsal, işlemsel ve bilişüstü bilgi kısımlardan oluşmaktadır. Alt boyutlarda dahi görüş ayrılığı olabilmektedir. Burada revize edilen sınıflamanın esnek bir yapı içerdiği belirtilmektedir [13].Çalışmada bu şekilde 
bilgi boyutunda olgusal, kavramsal, işlemsel ve bilişüstü bilgi alt boyutlarıyla düzeylendirme yapılmamıştır.

\section{KAYNAKLAR}

1. Crowe, A., C. Dirks, and M.P. Wenderoth, Biology in bloom: implementing Bloom's Taxonomy to enhance student learning in biology. CBE Life Sci Educ, 2008. 7(4): p. 36881.

2. Harden, R.M., Laidlaw J.M, Essential Sk1lls For A Medical Teacher. Written and Computer Based Assesment. 2012.

3. Dent J.A., Harden.R.M., A Practical Guide for Medical Teachers. 2013: p. 307.

4. Haladyna, T.M. and G.A. Kramer, The validity of subscores for a credentialing test. Eval Health Prof, 2004. 27(4): p. 349-68.

5. Collins, J., Education techniques for lifelong learning: writing multiple-choice questions for continuing medical education activities and self-assessment modules. Radiographics, 2006. 26(2): p. 543-51.

6. Cansever, Z., et al., What do trainers think about trainer training courses? J Pak Med Assoc, 2014. 64(5): p. 491-5.

7. Musal B., Eğitici Gelişim Programları: Dokuz Eylül Üniversitesi Tip Fakültesi Deneyimi Ege Eğitim Dergisi, 2003. 3(1 ): p. 81-88.
8. Gajjar, S., et al., Item and Test Analysis to Identify Quality Multiple Choice Questions (MCQs) from an Assessment of Medical Students of Ahmedabad, Gujarat. Indian J Community Med, 2014. 39(1): p. 17-20.

9. Gopalakrishnan, S. and P.M. Udayshankar, Question vetting: the process to ensure quality in assessment of medical students. J Clin Diagn Res, 2014. 8(9): p. XM01-XM03.

10. Moeen Uz, Z. and A. Badr, Evaluation of mini-essay questions (MEQ) and multiple choice questions (MCQ) as a tool for assessing the cognitive skills of undergraduate students at the Department of Medicine. Int J Health Sci (Qassim), 2011. 5(2 Suppl 1): p. 43-4.

11. Downing, S.M. and T.M. Haladyna, Validity threats: overcoming interference with proposed interpretations of assessment data. Med Educ, 2004. 38(3): p. 327-33.

12. Durak H.İ.,Solakoğlu Z. Tip Eğitiminin Temelleri. 2012.Sayfa: 69-83.

13. Eğitimde Program Geliştirme (Hedef Belirleme: Bilişsel, Duyuşsal ve Devinişsel Alanlar) Yrd.Doç.Dr Zeynel Kablan ,3.bask1, Ankara ,sayfa 127-159. 